\title{
Article \\ Antibiotic Use for Febrile Illness among Under-5 Children in Bangladesh: A Nationally Representative Sample Survey
}

\author{
Nora Samir ${ }^{1,+} \oplus^{-}$, Md. Zakiul Hassan ${ }^{2,3, *,+} \oplus$, Md. Abdullah Al Jubayer Biswas ${ }^{2, \dagger}$, Fahmida Chowdhury ${ }^{2}$, \\ Zubair Akhtar ${ }^{2}{ }^{\mathbb{D}}$, Raghu Lingam ${ }^{1}$, Sayera Banu ${ }^{2} \mathbb{D}$ and Nusrat Homaira ${ }^{1,4}{ }^{(1)}$ \\ 1 Discipline of Paediatrics, School of Women's and Children's Health, Faculty of Medicine, The University of \\ New South Wales, Sydney 2031, Australia; n.samir@unsw.edu.au (N.S.); r.lingam@unsw.edu.au (R.L.); \\ n.homaira@unsw.edu.au (N.H.) \\ 2 Programme for Emerging Infections, Infectious Disease Division, International Centre for Diarrhoeal Disease \\ Research, Bangladesh (icddr,b), Dhaka 1212, Bangladesh; jubayer.biswas@icddrb.org (M.A.A.J.B.); \\ fahmida_chow@icddrb.org (F.C.); zakhtar@icddrb.org (Z.A.); sbanu@icddrb.org (S.B.) \\ 3 Nuffield Department of Medicine, University of Oxford, Oxford OX3 9DU, UK \\ 4 Respiratory Department, Sydney Children's Hospital, Sydney 2031, Australia \\ * Correspondence: zhassan@icddrb.org \\ + These authors contributed equally to this work.
}

check for updates

Citation: Samir, N.; Hassan, M.Z.; Biswas, M.A.A.J.; Chowdhury, F.; Akhtar, Z.; Lingam, R.; Banu, S.; Homaira, N. Antibiotic Use for Febrile Illness among Under-5 Children in Bangladesh: A Nationally Representative Sample Survey. Antibiotics 2021, 10, 1153. https:// doi.org/10.3390/antibiotics10101153

Academic Editor: Mamoon Aldeyab

Received: 7 July 2021

Accepted: 22 September 2021

Published: 24 September 2021

Publisher's Note: MDPI stays neutral with regard to jurisdictional claims in published maps and institutional affiliations.

Copyright: (c) 2021 by the authors. Licensee MDPI, Basel, Switzerland. This article is an open access article distributed under the terms and conditions of the Creative Commons Attribution (CC BY) license (https:/ / creativecommons.org/licenses/by/ $4.0 /)$.

\begin{abstract}
Fever in children under five years of age is a common and predominantly self-limiting sign of illness. However, in low- and middle-income countries, antibiotics are frequently used in febrile children, although these children may not benefit from antibiotics. In this study, we explored the prevalence of, and factors associated with, antibiotic use in children under five years old with febrile illness in Bangladesh. We analysed data from the 2017-2018 Bangladesh Demographic and Health Survey to determine the prevalence of antibiotic use in children under five years of age with a febrile illness. We used a causal graph and performed a multivariable logistical regression to identify the factors associated with antibiotic use in children under five years old with febrile illness in Bangladesh. Of the 2784 children aged less than five years with fever included in our analysis, 478 (17\%, $95 \%$ CI $15 \%$ to $19 \%)$ received antibiotics. Unqualified sources, including unqualified providers and pharmacies, contributed to $60 \%$ of antibiotic prescriptions in children with fever, followed by the private medical sector $(29 \%)$ and the public sector $(23 \%)$. The highest use of antibiotics was found in children under six months of age (25\%). Children with parents who completed secondary or higher education were more likely to receive antibiotics (adjusted OR (aOR): 2.61 (95\% CI 1.63 to 4.16)) than children whose parents did not complete primary education. Educational interventions promoting rational use of antibiotics and improved regulations governing over the counter purchase of antibiotics in Bangladesh may improve antibiotic dispensing practices.
\end{abstract}

Keywords: febrile illness; under-5 aged children; antimicrobial use; antibiotic; Bangladesh

\section{Introduction}

Febrile illnesses in children under five years of age are common. On average, children worldwide experience three to six episodes of febrile diseases per year [1,2]. This rate is even higher in children living in low and middle-income countries (LMICs) [3,4]. Fever is also the single most common reason for children to be seen by medical practitioners and is one of the most frequent presenting symptoms in emergency department visits [2]. Studies suggest most acute febrile illnesses in children requiring ambulatory care visits have a viral aetiology and do not require antibiotics [5]. These illnesses include acute respiratory infections (ARIs), accounting for $50-75 \%$ of febrile presentations at outpatient clinics, and gastroenteritis, accounting for $10-25 \%$ of febrile illnesses. Clinical practice guidelines (CPGs), such as the Integrated Management of Childhood Illness (IMCI), aim to standardise the symptomatic management of fever in children [6]. These guidelines 
promote the rational use of antimicrobials by recommending antibiotics be exclusively prescribed to children who are presumed to have a disease that can be treated using antibiotics, based on World Health Organisation (WHO) recommendations [7]. Despite these recommendations, healthcare providers erring on the side of caution continue to prescribe antibiotics frequently to patients who may not have an illness with bacterial aetiology [7]. Factors contributing to the irrational use of antibiotics in febrile children include diagnostic uncertainty, inadequate knowledge and experience, and pressure from anxious parents [8-10].

Bangladesh is a LMIC where more than half of the antibiotics used in children are thought to be inappropriately prescribed, dispensed, or sold [11-13]. This inappropriate antibiotic usage can be attributed to several factors within Bangladesh's pluralistic healthcare system, which disparate actors govern: government, private sectors, non-governmental organisations (NGOs), and informal sectors, including unqualified providers and pharmacies [14]. One of the significant contributors to the inappropriate use of antibiotics in Bangladesh is unregulated 'drug shops' and unqualified providers who supply antibiotics to a large proportion of the population, often in incorrect doses [15]. This overuse of antibiotics risks several consequences at the individual, system, and population levels. Among these potential consequences is the emergence of antimicrobial resistance (AMR), increased risk of developing chronic diseases such as asthma, increased healthcare costs, and wasted resources $[8,16]$. In line with the WHO Global Action Plan on Antimicrobial Resistance (GAP), Bangladesh has taken the first step to address AMR [16]. In 2018, in collaboration with other development partners, the Government of Bangladesh undertook a situational analysis. It published the National Action Plan (NAP) on AMR containment [17]. The objectives of the NAP include promoting the rational use of antibiotics, establishing a multi-sectoral approach for the planning and implementation of antimicrobial resistance containment activities, and strengthening regulatory provisions and surveillance systems for AMR containment. To achieve these objectives and monitor trends over time, population-level baseline data on the use of antibiotics for febrile illnesses-one of the most common presenting symptoms in children-is crucial.

Several studies have examined antibiotic dispensing patterns in Bangladeshi children hospitalised for diarrhoeal disease and pneumonia, but there are limited data on the overall use of antibiotics for febrile illnesses [12,18-24]. Additionally, hospital-based studies provide data on the use of antibiotics in small groups of children with more severe than average symptoms of diseases that may warrant antibiotic use. Still, such studies do not provide information that accurately reflects the general population. There are also limited population-level data on the socio-demographic factors associated with antibiotic usage for febrile illness in children, and such data may inform targeted interventions that improve antimicrobial stewardship. Therefore, we examined the prevalence and associated factors with antibiotic usage in children under five years old with febrile illness in Bangladesh utilising nationally representative, population-based sample survey data.

\section{Results}

\subsection{Participant Socio-Demographic Characteristics}

Of 8421 children surveyed, 2784 (33\%) had experienced fever in the preceding two weeks. Of 2784 children with fever, $254(9 \%)$ also had symptoms of acute respiratory infection (ARI), and $396(14 \%)$ also had diarrhoea. A total of $478(17 \%)$ children with fever received antibiotics for their illness and were thus included in this analysis. Twenty five percent of children who received antibiotics for their febrile disease were aged less than six months old, and nine percent were between 48 and 59 months. Children of parents with secondary complete or higher level of education had the highest percentage of antibiotic use for febrile illness (Table 1). 
Table 1. Prevalence of antibiotic usage in febrile children according to both children and parents' background and treatmentseeking characteristics, 2017-2018 Bangladesh $(n=8421)$.

\begin{tabular}{|c|c|c|c|c|c|}
\hline & \multicolumn{5}{|c|}{ Fever in Children Less than Five Years of Age } \\
\hline & \multirow{2}{*}{$\begin{array}{l}\text { Fever in Children } \\
\text { Under the Age of } \\
\text { Five }(n=2784)\end{array}$} & \multicolumn{4}{|c|}{ Antibiotic Usage } \\
\hline & & $n$ & $\%$ & $95 \% \mathrm{CI}$ & $p$-Value \\
\hline Total & 2784 & 478 & 17 & $(15,19)$ & \\
\hline \multicolumn{6}{|l|}{ Age in months } \\
\hline$<6$ & 270 & 66 & 25 & $(19-31)$ & \multirow{6}{*}{$<0.001$ * } \\
\hline $6-11$ & 372 & 84 & 23 & $(18-28)$ & \\
\hline $12-23$ & 680 & 142 & 21 & $(17-25)$ & \\
\hline $24-35$ & 552 & 80 & 14 & $(11-18)$ & \\
\hline $36-47$ & 472 & 60 & 13 & $(10-17)$ & \\
\hline $48-59$ & 438 & 44 & 10 & $(7-14)$ & \\
\hline \multicolumn{6}{|l|}{ Sex of child } \\
\hline Male & 1502 & 262 & 17 & $(15-20)$ & \multirow[t]{2}{*}{0.693} \\
\hline Female & 1282 & 216 & 17 & $(14-19)$ & \\
\hline \multicolumn{6}{|l|}{$\begin{array}{l}\text { Type of place of } \\
\text { residence }\end{array}$} \\
\hline Rural & 714 & 111 & 18 & $(16,20)$ & \multirow[t]{2}{*}{0.241} \\
\hline Urban & 2070 & 367 & 16 & $(13-19)$ & \\
\hline \multicolumn{6}{|l|}{ Wealth index } \\
\hline Poorest & 612 & 107 & 17 & $(14-21)$ & \multirow{5}{*}{0.495} \\
\hline Poorer & 569 & 96 & 17 & $(14-21)$ & \\
\hline Middle & 548 & 96 & 17 & $(14-21)$ & \\
\hline Richer & 594 & 113 & 19 & $(16,23)$ & \\
\hline Richest & 461 & 66 & 14 & $(11-18)$ & \\
\hline \multicolumn{6}{|l|}{$\begin{array}{l}\text { Highest education } \\
\text { level of parent }\end{array}$} \\
\hline No education & 103 & 12 & 12 & $(7-21)$ & \multirow{5}{*}{0.006} \\
\hline $\begin{array}{c}\text { Primary } \\
\text { incomplete }\end{array}$ & 357 & 37 & 10 & $(7-14)$ & \\
\hline Primary complete & 289 & 54 & 19 & $(14-24)$ & \\
\hline $\begin{array}{l}\text { Secondary } \\
\text { incomplete }\end{array}$ & 1271 & 221 & 17 & $(15-20)$ & \\
\hline $\begin{array}{c}\text { Secondary } \\
\text { complete or higher }\end{array}$ & 759 & 153 & 20 & $(17-24)$ & \\
\hline \multicolumn{6}{|l|}{$\begin{array}{l}\text { First source of } \\
\text { fever treatment }\end{array}$} \\
\hline Public sector & 255 & 58 & 23 & $(17-29)$ & \multirow{7}{*}{$<0.001 *$} \\
\hline $\begin{array}{c}\text { Private medical } \\
\text { sector }\end{array}$ & 465 & 133 & 29 & $(24-34)$ & \\
\hline Pharmacy & 1277 & 226 & 18 & $(15-20)$ & \\
\hline $\begin{array}{l}\text { Unqualified } \\
\text { provider }\end{array}$ & 294 & 59 & 20 & $(15-26)$ & \\
\hline NGO sector & 7 & 1 & 14 & $(3-48)$ & \\
\hline Other source & 90 & 1 & 2 & $(0-11)$ & \\
\hline No treatment & 398 & 0 & 0 & 0 & \\
\hline
\end{tabular}




\subsection{Prevalence of Antibiotic Use in Febrile Children}

The total percentage of febrile children who were given antibiotics was almost $17 \%$. In addition, statistically significant associations were found between the prevalence of antibiotic usage in febrile children and children's age, parents' highest level of education, and first source of treatment (Table 1).

\subsection{Factors Related to the Use of Antibiotics in Children Who Had a Fever}

The results from logistic regression analysis indicate the unadjusted and adjusted odd ratios (ORs) and the 95\% confidence intervals (CIs) for the variables associated with antibiotic usage in children under five years old. Children who reported the private medical sector as the first source of antibiotics were 1.66 times more likely (95\% CI 1.09 to 2.50) to use antibiotics than children who reported pharmacy as a source of antibiotics (Table 2). The odds of using antibiotic was almost three times (95\% CI 1.83 to 4.47) higher in children aged less than six months compared with older children (Table S1). Moreover, children with parents who completed a secondary or higher level of education were 2.61 times $(95 \%$ CI 1.63 to 4.16$)$ more likely to report the use of antibiotics for children with fever than parents with lower levels of education (Table S2).

Table 2. Multivariable logistic regression model to determine the association between 1st source of treatment and antibiotic usage in children under five years old for any febrile illness, 2017-2018 Bangladesh.

\begin{tabular}{|c|c|c|c|c|}
\hline \multicolumn{5}{|c|}{ Model 1-First Source of Treatment Adjusting for Age, Sex, Type of Place of Residence, Wealth Index, Parents' Highest Level of Education } \\
\hline & \multicolumn{4}{|c|}{ Antibiotic Usage in Children under the Age of Five Year with Fever } \\
\hline & UOR $(95 \% \mathrm{CI})$ & $p$-Value & AOR $(95 \% \mathrm{CI})$ & $p$-Value \\
\hline \multicolumn{5}{|l|}{ Age in months } \\
\hline$<6$ & $2.86(1.83-4.47)$ & $<0.001 *$ & $3.08(1.95-4.88)$ & $<0.001 *$ \\
\hline $6-11$ & $2.58(1.62-4.11)$ & $<0.001$ * & $2.25(1.4-3.63)$ & 0.001 * \\
\hline $12-23$ & $2.33(1.49-3.65)$ & $<0.001 *$ & $2.31(1.46-3.66)$ & $<0.001 *$ \\
\hline $24-35$ & $1.49(0.91-2.43)$ & 0.110 & $1.37(0.83-2.25)$ & 0.215 \\
\hline $36-47$ & $1.29(0.79-2.11)$ & 0.307 & $1.29(0.79-2.11)$ & 0.316 \\
\hline $48-59$ & Reference & & Reference & \\
\hline \multicolumn{5}{|l|}{ Sex of child } \\
\hline Female & $0.96(0.77-1.19)$ & 0.693 & $1.04(0.82-1.31)$ & 0.752 \\
\hline Male & Reference & & Reference & \\
\hline \multicolumn{5}{|l|}{ Type of place of residence } \\
\hline Rural & $1.17(0.90-1.53)$ & 0.241 & $1.15(0.85-1.56)$ & 0.365 \\
\hline Urban & Reference & & Reference & \\
\hline \multicolumn{5}{|l|}{ Wealth index } \\
\hline Poorest & $0.90(0.64-1.27)$ & 0.552 & $1.19(0.82-1.75)$ & 0.362 \\
\hline Poorer & $0.87(0.63-1.18)$ & 0.374 & $1.09(0.78-1.53)$ & 0.611 \\
\hline Middle & $0.90(0.66-1.24)$ & 0.518 & $1.02(0.73-1.43)$ & 0.914 \\
\hline Richest & $0.72(0.51-1.01)$ & 0.058 & $0.63(0.42-0.93)$ & 0.021 \\
\hline Richer & Reference & & Reference & \\
\hline \multicolumn{5}{|l|}{$\begin{array}{l}\text { Highest educational level } \\
\text { of parent }\end{array}$} \\
\hline No education & $1.17(0.56-2.44)$ & 0.684 & $1.20(0.55-2.61)$ & 0.647 \\
\hline Primary complete & $1.98(1.22-3.22)$ & $0.006 *$ & $1.65(0.98-2.76)$ & 0.058 \\
\hline \multirow{3}{*}{$\begin{array}{l}\text { Secondary incomplete } \\
\text { Secondary complete } \\
\text { or higher } \\
\text { Primary incomplete }\end{array}$} & $1.8(1.19-2.72)$ & $0.006^{*}$ & $1.65(1.04-2.62)$ & $0.032 *$ \\
\hline & $2.15(1.41-3.28)$ & $<0.001$ * & $2.13(1.29-3.49)$ & $0.003 *$ \\
\hline & Reference & & Reference & \\
\hline \multicolumn{5}{|l|}{$\begin{array}{l}\text { First source of fever } \\
\text { treatment }\end{array}$} \\
\hline Public sector & $1.36(0.94-1.97)$ & 0.096 & $1.19(0.73-1.94)$ & 0.485 \\
\hline Private medical sector & $1.86(1.38-2.51)$ & $<0.001$ * & $1.66(1.09-2.50)$ & 0.017 * \\
\hline Unqualified provider & $1.17(0.83-1.66)$ & 0.363 & $0.92(0.65-1.30)$ & 0.632 \\
\hline Pharmacy & Reference & & Reference & \\
\hline
\end{tabular}

* A $p$-value less than 0.05 was significant. 


\section{Discussion}

Our results showed that around $17 \%$ (95\% CI 15-19) of children under five years of age with febrile illness received antibiotics. If we extrapolate our estimates to about 16.7 million children in Bangladesh, we estimated that 5.5 million children had the fever, with an estimated 943,186 receiving antibiotics [25]. Our findings are comparable to the proportion of children who received antibiotics for fever in other LMICs, as reported in a recent systematic analysis of 132 national surveys from 73 LMICs (49.6\%; range 12.2-82.6\%) [26].

Nearly $60 \%$ of antibiotics were obtained from unqualified sources, including pharmacies and unqualified providers. This is alarming since most pharmacies in Bangladesh are run by unqualified practitioners who provide antibiotics without a prescription [27]. Several studies have reported the overuse of antibiotics obtained from unqualified providers and drug shops in Bangladesh, and $80-90 \%$ of drug shops and medicine vendors operate without a license $[8,13,19,28]$. Additionally, the adequate supervision and inspection of drug outlets are complicated by the limited availability of drug inspectors (i.e., one drug inspector supervises 2236 pharmacy shops) [6]. Initiatives, such as the 'model pharmacy', which accredit pharmacies for meeting high standards of practice, may help to reduce over the counter purchases of antibiotics [29].

Our data indicated that $29 \%$ of antibiotic use for febrile illness came from the private medical sector and $23 \%$ from the public sector. Additionally, children who went to the private sector were significantly 1.66 times more likely (95\% CI 1.09-2.50) to receive antibiotics compared to those who went to a pharmacy for treatment. The unadjusted and adjusted effect size was nearly similar, suggesting that any child's age in months, sex, type of place of residence, wealth index, parents' highest level of education had little impact on the association. These results are consistent findings from previous literature, which indicates that in LMICs, private healthcare providers, particularly informal providers, contribute to a significant percentage of antibiotic dispensing [30]. Consistent with our findings, several studies conducted in LMICs have revealed higher paediatric antibiotics prescribed in the private sector than in the public sector [31]. This trend could be explained by public health facilities not being able to meet the high demand for their services. Long waiting times and lack of drug availability in Bangladeshi public health facilities may also motivate patients to seek healthcare advice and obtain antibiotics from the private medical sector [8,32].

Our study showed that children whose parents completed secondary and higher education were almost twice as likely to receive antibiotics for fever than children with parents who did not complete primary education. This is contrary to the existing literature on LMICs, which suggests that low parental educational levels are associated with higher use of antibiotics in children [33]. Parents with higher education are often more concerned about their children's health but do not necessarily have higher awareness of the effects of antibiotic use [34]. This is consistent with our data, which indicates that $46 \%(132 / 285)$ and $27 \%(78 / 285)$ of parents who received antibiotics for children with febrile illness from unqualified sources (such as pharmacies and unqualified providers) had an incomplete secondary education and a completed secondary or higher education, respectively. This is significantly higher than parents with an incomplete primary education who received antibiotics for children with febrile illness from unqualified sources $(10 \%(28 / 285))$. This could explain our finding that antibiotic use was higher in children with more educated parents. Although we cannot comment on whether parents' education is a predictor of inappropriate use of antibiotics, it is still crucial to improve public awareness on appropriate antibiotic use through community-based interventions [30].

Our analysis used a population-based, national representative dataset of more than 8400 families and used standardised data collection methods. Thus, the findings can be extrapolated at a national level. Despite this study's strengths, it has certain limitations. The most important limitation of our study is the lack of available information on fever aetiology. As such, we could not assess appropriate versus inappropriate antibiotic use. However, we aimed to determine the prevalence of use of antibiotics. Further, our outcome measure was based on self-reported data, which may have led to recall bias, such that parents did not 
accurately report types of symptoms and treatments. This potential influence of recall bias was likely reduced by trained BDHS interview teams asking parents to show the packets of medicines dispensed to their children.

\section{Materials and Methods}

\subsection{Data Sources}

We used data from the most recent 2017-2018 (published in 2021) Bangladesh Demographic and Health Survey (BDHS), a nationally representative, cross-sectional household survey that collects child health data, including treatment practices and contact with health services for childhood illnesses [35]. These data are anonymised and publicly available for secondary analysis on request.

\subsection{Study Population and Sampling Strategies}

The BDHS used a two-stage stratified sampling design, whereby 675 enumeration areas (EAs) were sampled in the first stage of sampling using a probability proportional to size approach. EAs are geographical areas that include 113 households from a town, a small village, or a section of a larger village. The Bangladesh Bureau of Statistics compiled a list of EAs for the People's Republic of Bangladesh's 2011 population census. BDHS 2017-2018 utilised that list of EAs as the sampling frame-250 EAs were selected from urban areas and 425 from rural areas. The second stage of sampling included selecting a systematic sample of 30 households per EA to provide estimates for key factors that were more statistically trustworthy for the entire population. Finally, the survey was administered to a total of 20,160 households and completed in 19,584 residential households. In these households, 20,376 women aged 15-49 were identified, and 20,127 were interviewed by trained personnel. The response rate was approximately $99 \%$. To obtain information on antibiotic usage, mothers were asked about the history of any febrile illness and treatment sought for that febrile illness in children aged 0-59 months in the two weeks preceding the interview. We included all children who had a history of taking antibiotics in the preceding two weeks due to fever from any cause and could have included but not limited to fever due to ARI or diarrhoea. The Bangladesh Demographic and Health Survey 2017-2018 report contains detailed information on the sampling strategies and execution [35].

\subsection{Data Collection Tools}

Household Questionnaire, Women's Questionnaire, Biomarker Questionnaire, Verbal Autopsy Questionnaires, Community Questionnaire, and Fieldworker Questionnaire were among the six types of questionnaires used in the 2017-2018 BDHS. The Women's Questionnaire was used to gather data on background demographic features, fertility, family planning, breastfeeding, prenatal and postnatal treatment, infant immunisation, child health and nutrition, and husband's characteristics. Each of the six types of questionnaires was adapted, pretested, and validated in the context of Bangladesh. The detailed questionnaires are publicly available [35].

\subsection{Data Collection}

A trained interviewing team collected data for the BDHS between 24 October 2017 and 15 March 2018. Each team was led by a male supervisor, assisted by a female field editor, and comprised five female interviewers, two health technicians, and one logistical staff member. The team obtained informed consent from all participants before administrating the interview. The National Institute of Population Research and Training (NIPORT), Ministry of Health and Family Welfare (MOHFW), ICF, and Mitra and Associates quality control team monitored data collection. Data processing was conducted at Mitra and Associates' offices using Census and Survey Processing System (CSPro) software [35]. 


\subsection{Outcome Variable}

The outcome variable for our study was the prevalence of antibiotic use for any reported/documented fever in children under five years of age. We used the Women's Questionnaire to extract data relevant to this outcome. The Women's Questionnaire asked mothers if their children under the age of five had a fever within the two weeks before the survey's completion. Participants were then asked where they sought help or care and what kind of fever medication they used. We aggregated data on all the antibiotics for which information was collected (i.e., Beta-lactum, Macrolides, Quinolone, Cephalosporin, Cotrimoxazole, Gentamycin, and Metronidazole) to calculate the prevalence of antibiotic use [35].

\subsection{Explanatory Variables}

We investigated seven associated factors with antibiotic usage in children with febrile illnesses based on existing literature $[13,26,31,32,36-44]$. Explanatory variables utilised in this study are defined in Table 3.

Table 3. Measurement of explanatory variables.

\begin{tabular}{|c|c|}
\hline Variable & Definition \\
\hline Age in months & $\begin{array}{l}\text { The age of the children was computed using the date of birth provided or from the } \\
\text { children's birth history. There were four age groups for children that were less than } \\
\text { six months, 6-10 months, } 12-23 \text { months, } 24-35 \text { months, } 36-47 \text { months, and } \\
48-59 \text { months. }\end{array}$ \\
\hline Sex of child & Children's sexes are classified as male or female. \\
\hline Type of place of residence & $\begin{array}{l}\text { The term "place of residence" referred to the region where children resided and was } \\
\text { classified as either urban or rural. }\end{array}$ \\
\hline Wealth index & $\begin{array}{l}\text { A composite indicator summed up the standard of living a household has acquired up } \\
\text { to a point. The wealth index was produced by obtaining data on the number of assets } \\
\text { owned by each household. A composite factor score was computed through principal } \\
\text { component analysis and then divided into five quintiles (poorest: q1; poorer: q2; } \\
\text { middle: q3; richer: q4; richest: q5). }\end{array}$ \\
\hline Highest educational level of parent & $\begin{array}{l}\text { It was a composite variable that indicated the highest education level of father and } \\
\text { mother. The variable was categorised as follows: no education (both were illiterate), } \\
\text { primary incomplete (either father or mother had education up to grade 5), primary } \\
\text { complete (either father or mother completed grade 5), secondary incomplete (any of } \\
\text { them had education up to grade 10), secondary incomplete or higher (any of them } \\
\text { completed grade } 10 \text { or above). }\end{array}$ \\
\hline \multirow[t]{7}{*}{ First source of fever treatment } & $\begin{array}{l}\text { Type of health facility where mothers first sought advice and/or received antibiotics } \\
\text { for their children's fever. This variable included the following categories of } \\
\text { health facilities. }\end{array}$ \\
\hline & $\begin{array}{c}\text { Public sector: This category includes medical college hospitals, specialised } \\
\text { government hospitals, district hospitals (DH), mother and child welfare centre } \\
\text { (MCWC), upazila health complexes (UHC), union health and family welfare centres } \\
\text { (UH\&FWC), community clinics (CC), satellite clinics/epi outreach, and other public } \\
\text { sector facilities. }\end{array}$ \\
\hline & $\begin{array}{l}\text { Private medical sector: Private medical facilities such as private medical college } \\
\text { hospitals, private hospitals, private clinics, and certified doctor's chambers were } \\
\text { included in the private medical sector category. }\end{array}$ \\
\hline & Pharmacy: Pharmacy/drug store was included in this category. \\
\hline & Unqualified provider: Non-qualified doctor's chamber was included in this category. \\
\hline & $\begin{array}{l}\text { NGO sector: The non-government organisation (NGO) sector category used to express } \\
\text { the NGO sector health facilities as a source of advice and/or antibiotics were NGO } \\
\text { statis clinic, NGO field worker, and another NGO sector. }\end{array}$ \\
\hline & $\begin{array}{c}\text { Other: The other category was used to express other health facilities including } \\
\text { homeopaths and other traditional healers. }\end{array}$ \\
\hline
\end{tabular}




\subsection{Statistical Analysis}

We summarised the study participants' characteristics using descriptive statistics such as frequency, percentage, and cross-tabulation. We performed bivariable logistic regression analysis to determine the crude association between getting antibiotics for febrile illness and selected explanatory factors in children under the age of five. The outputs of bivariable analysis were reported as unadjusted odds ratio (UORs) with $95 \%$ confidence interval (95\% CI). A conceptual framework technique was used to explore the causal pathways between the outcome variable and the explanatory variables based on empirical knowledge from the findings of previous studies and the authors' experience (Figure 1) [26,31,32,36-40,42-47]. Details about causal graphs are described in Jewell 2003 [48]. The conceptual framework's arrows indicated the explanatory variable's causal effect. The first source of treatments influenced children's antibiotic usage according to their age, sex, parents' highest level of education, wealth index, and type of residence [34,37,40,42]. We calculated the impact of the first source of treatments using model 1. Likewise, the arrow from children's age to antibiotic usage depicted the influence of age on their antibiotic usage [34]. We assessed the overall effect of age in model 2. Similarly, the household wealth index and parents ${ }^{\prime}$ education affect children's antibiotic usage and have an interaction effect [41-44]. We used model 3 to account for the effect of the household wealth index and the parents education level. For each multivariable logistic regression model, outputs were estimated and reported as adjusted odds ratios (AOR) with 95\% CI. All tests were two-tailed and, at a significance level of $5 \%$, were deemed significant. Stata software package (version 15; StataCorp, College Station, TX, USA) was used to conduct all data analysis.



Figure 1. Conceptual framework on associated factors that influenced the children's antibiotic use for any febrile illness.

\section{Conclusions}

In conclusion, the findings of this study provide a comprehensive baseline assessment of antibiotic use for febrile illness among children aged less than five years in Bangladesh across rural and urban locations and among different health care settings. The data from this study may help prioritise, target, implement, and evaluate interventions that improve antibiotic dispensing practices for febrile children in Bangladesh. 
Supplementary Materials: The following are available online at https:/ /www.mdpi.com/article/ 10.3390/antibiotics10101153/s1, Table S1: Multivariable logistic regression model to determine the association between age and antibiotic usage in children under five years old for any febrile illness, 2017-18 Bangladesh, Table S2: Multivariable logistic regression model to determine the association between wealth index and highest educational level of parent with antibiotic usage in children under five years old for any febrile illness, 2017-18 Bangladesh.

Author Contributions: Conceptualisation, M.Z.H.; methodology, M.A.A.J.B.; software, M.A.A.J.B.; validation, N.H., M.Z.H. and R.L.; formal analysis, M.A.A.J.B. and N.S.; investigation, N.S., M.A.A.J.B., N.H., M.Z.H.; resources, N.H. and M.Z.H.; data curation, M.A.A.J.B., N.H. and M.Z.H.; writing—original draft preparation, N.S. and M.A.A.J.B.; writing—review and editing, N.S., M.Z.H., N.H., F.C., Z.A., R.L., S.B.; visualisation, M.A.A.J.B.; supervision, N.H.; project administration, N.H. and M.Z.H. All authors have read and agreed to the published version of the manuscript.

Funding: This research received no external funding. NH is supported by a research fellowship of the National Health and Medical Research Council of the Australian Government (GNT1158646).

Institutional Review Board Statement: This study was based on the secondary analysis of publicly available data in the public domain/online (https:/ / dhsprogram.com/data/available-datasets.cfm) that has been stripped of any identifying information. We contacted with MEASURE DHS/ICF International, and they gave us permission to download and utilised the data. The survey was conducted in accordance with the appropriate data collecting methods, and it was approved by the National Research Ethics Committee (NREC) of the Bangladesh Ministry of Health and Family Welfare. In accordance with the DHS, signed informed permission was acquired from all survey participants before to their participation in the study.

Informed Consent Statement: Not applicable.

Data Availability Statement: The data presented in this study are available on request from the corresponding author.

Acknowledgments: We want to acknowledge the contribution of the Bangladesh health facility survey (BHFS), National Institute of Population Research and Training (NIPORT/Bangladesh), MEASURE DHS as well as ICF International teams (of USA) for their efforts to collect and give permission to use the Bangladesh health facility survey 2017, data. We want to acknowledge the contribution of International Diarrheal Diseases Research, Bangladesh (icddr, b) to permit writing this research article. We also would like to acknowledge the donors providing unrestricted support to icddr, b's research efforts. icddr,b is grateful to the governments of Bangladesh, Canada, Sweden and the UK for providing core/unrestricted support. We also thank Nicola Paul for her contributions to this paper.

Conflicts of Interest: The authors declare no conflict of interest.

\section{References}

1. Hay, A.D.; Heron, J.; Ness, A.J.F.P. The prevalence of symptoms and consultations in pre-school children in the Avon Longitudinal Study of Parents and Children (ALSPAC): A prospective cohort study. Fam. Pract. 2005, 22, 367-374. [CrossRef]

2. Craig, J.C.; Williams, G.J.; Jones, M.; Codarini, M.; Macaskill, P.; Hayen, A.; Irwig, L.; Fitzgerald, D.A.; Isaacs, D.; McCaskill, M. The accuracy of clinical symptoms and signs for the diagnosis of serious bacterial infection in young febrile children: Prospective cohort study of 15,781 febrile illnesses. BMJ 2010, 340, c1594. [CrossRef] [PubMed]

3. Fink, G.; D'Acremont, V.; Leslie, H.H.; Cohen, J. Antibiotic exposure among children younger than 5 years in low-income and middle-income countries: A cross-sectional study of nationally representative facility-based and household-based surveys. Lancet Infect. Dis. 2020, 20, 179-187. [CrossRef]

4. Herlihy, J.M.; D'Acremont, V.; Burgess, D.C.H.; Hamer, D.H. Diagnosis and treatment of the febrile child. Reprod. Matern. Newborn Child Health 2016, 137. [CrossRef]

5. Al-Eissa, Y.A.; Ghazal, S.S.; Al-Zamil, F.A.; Al-Salloum, A.A.; Al-Omair, A.O.; Al-Nasser, M.N. Pattern of febrile illnesses in children seen at a pediatric ambulatory care setting. J. Fam. Community Med. 2000, 7, 61-65.

6. García Sierra, A.M.; Ocampo Cañas, J.A. Integrated Management of Childhood Illnesses implementation-related factors at 18 Colombian cities. BMC Public Health 2020, 20, 1122. [CrossRef]

7. World Health Organization. WHO Informal Consultation on Fever Management in Peripheral Health Care Settings: A Global Review of Evidence and Practice; WHO: Geneva, Switzerland, 2013.

8. Poirier, M.P.; Collins, E.P.; McGuire, E. Fever phobia: A survey of caregivers of children seen in a pediatric emergency department. Clin. Pediatrics 2010, 49, 530-534. [CrossRef] 
9. Whaley, L.E.; Businger, A.C.; Dempsey, P.P.; Linder, J.A.J.B.F.P. Visit complexity, diagnostic uncertainty, and antibiotic prescribing for acute cough in primary care: A retrospective study. BMC Fam. Pract. 2013, 14, 120. [CrossRef]

10. Sayeed, M.A.; Iqbal, N.; Ali, M.S.; Rahman, M.M.; Islam, M.R.; Jakaria, M.J.B.P.J. Survey on Antibiotic Practices in Chittagong City of Bangladesh. Bangladesh Pharm. J. 2015, 18, 174-178. [CrossRef]

11. Chowdhury, F.; Rahman, M.; Huq, M.; Begum, S. Rationality of drug uses: Its Bangladeshi perspectives. Mymensingh Med. J. MMJ 2006, 15, 215-219. [CrossRef]

12. Datta, S.K.; Paul, T.R.; Monwar, M.; Khatun, A.; Islam, M.R.; Ali, M.A.; Barman, R.K.; Rahman, B.M.; Wahed, M.I.I.J.I.J.P.P.S. Patterns of prescription and antibiotic use among outpatients in a tertiary care teaching hospital of Bangladesh. Int. J. Pharm. Pharm. Sci. 2016, 8, 54. [CrossRef]

13. Hassan, M.Z.; Monjur, M.R.; Biswas, M.A.A.J.; Chowdhury, F.; Kafi, M.A.H.; Braithwaite, J.; Jaffe, A.; Homaira, N. Antibiotic use for acute respiratory infections among under-5 children in Bangladesh: A population-based survey. BMJ Glob. Health 2021, 6, e004010. [CrossRef]

14. Bloom, G.; Wilkinson, A.; Tomson, G.; Awor, P.; Zhang, X.; Ahmed, S.M.; Khan, W.A.; Blessing, V.; Wang, L.; Liang, X. Addressing Resistance to Antibiotics in Pluralist Health Systems; STEPS Centre: Brighton, UK, 2015.

15. Faiz, M.A.; Basher, A. Antimicrobial resistance: Bangladesh experience. Reg. Health Forum 2011, 15, 1-8.

16. WHO. Global Action Plan on Antimicrobial Resistance; World Health Organization: Geneva, Switzerland, 2015.

17. Global Antibiotic Resistance Partnership—Bangladesh, GARP-Bangladesh National Working Group. Antibiotic Use and Resistance in Bangladesh: Situation Analysis and Recommendations on Antibiotic Resistance; Center for DiseaseDynamics, Economics \& Policy (CDDEP): Washington, DC, USA; New Delhi, India, 2018.

18. Rogawski, E.T.; Platts-Mills, J.A.; Seidman, J.C.; John, S.; Mahfuz, M.; Ulak, M.; Shrestha, S.K.; Soofi, S.B.; Yori, P.P.; Mduma, E.; et al. Use of antibiotics in children younger than two years in eight countries: A prospective cohort study. Bull. World Health Organ. 2017, 95, 49-61. [CrossRef] [PubMed]

19. Akter, F.U.; Heller, D.; Smith, A.; Rahman, M.M.; Milly, A.F. Antimicrobial use in paediatric wards of teaching hospitals in Bangladesh. Mymensingh Med. J. MMJ 2004, 13, 63-66. [PubMed]

20. Alam, M.B.; Ahmed, F.U.; Rahman, M.E. Misuse of drugs in acute diarrhoea in under-five children. Bangladesh Med. Res. Counc. Bull. 1998, 24, 27-31. [PubMed]

21. Rashid, M.M.; Chisti, M.J.; Akter, D.; Sarkar, M.; Chowdhury, F. Antibiotic use for pneumonia among children under-five at a pediatric hospital in Dhaka city, Bangladesh. Patient Prefer Adherence 2017, 11, 1335-1342. [CrossRef]

22. Ahmed, S.; Farzana, F.D.; Ferdous, F.; Chisti, M.J.; Malek, M.A.; Faruque, A.S.G.; Das, S.K.J.S.J.C.M. Urban-rural differentials in using antimicrobials at home among under-5 children with diarrhea. Sci. J. Clin. Med. 2013, 2, 81-86. [CrossRef]

23. Ahmed, S.; Korpe, P.; Ahmed, T.; Chisti, M.J.; Faruque, A.S.G. Burden and Risk Factors of Antimicrobial Use in Children Less Than 5 Years of Age with Diarrheal Illness in Rural Bangladesh. Am. J. Trop. Med. Hyg. 2018, 98, 1571-1576. [CrossRef]

24. Fahad, B.M.; Matin, A.; Shill, M.C.; Asish, K.D. Antibiotic usage at a primary health care unit in Bangladesh. Australas. Med. J. 2010, 3, 414-421. [CrossRef]

25. UNICEF. Nutrition Country Profiles. Available online: https:/ / data.unicef.org/resources/nutrition-country-profiles/ (accessed on 22 June 2021).

26. Allwell-Brown, G.; Hussain-Alkhateeb, L.; Kitutu, F.E.; Strömdahl, S.; Mårtensson, A.; Johansson, E.W. Trends in reported antibiotic use among children under 5 years of age with fever, diarrhoea, or cough with fast or difficult breathing across low-income and middle-income countries in 2005-17: A systematic analysis of 132 national surveys from 73 countries. Lancet Glob. Health 2020, 8, e799-e807. [CrossRef]

27. SIAPS. Baseline Study of Private Drug Shops in Bangladesh: Findings and Recommendations; Management Sciences for Health: Arlington, VA, USA, 2015.

28. Naha, P.; Unicomb, L.; Lucas, P.J.; Uddin, M.R.; Islam, M.A.; Nizame, F.A.; Khisa, N.; Akter, S.M.S.; Rousham, E.K. What contributes to inappropriate antibiotic dispensing among qualified and unqualified healthcare providers in Bangladesh? A qualitative study. BMC Health Serv. Res. 2020, 20, 656. [CrossRef]

29. Sultana, J. Patients' perception and satisfaction on model pharmacies in Dhaka City, Bangladesh. Bangladesh Pharm. J. 2018, 21, 47-54. [CrossRef]

30. Sulis, G.; Gandra, S. Access to antibiotics: Not a problem in some LMICs. Lancet Glob. Health 2021, 9, e561-e562. [CrossRef]

31. Ab Rahman, N.; Teng, C.L.; Sivasampu, S. Antibiotic prescribing in public and private practice: A cross-sectional study in primary care clinics in Malaysia. BMC Infect. Dis. 2016, 16, 1-8. [CrossRef]

32. Wang, T.; Le Viet, T.; Son, T.T.; Makuka, G.J.; Zheng, C.; Lewycka, S.; van Doorn, R. Social and Health Seeking Determinants of Antibiotic Use in Vietnamese Children Under 5: Analysis of National Household Survey Data. medRxiv 2019, 19013292. [CrossRef]

33. Zanichelli, V.; Tebano, G.; Gyssens, I.C.; Vlahović-Palčevski, V.; Monnier, A.A.; Stanic Benic, M.; Harbarth, S.; Hulscher, M.; Pulcini, C.; Huttner, B.D. Patient-related determinants of antibiotic use: A systematic review. Clin. Microbiol. Infect 2019, $25,48-53$. [CrossRef]

34. Ocan, M.; Obuku, E.A.; Bwanga, F.; Akena, D.; Richard, S.; Ogwal-Okeng, J.; Obua, C. Household antimicrobial self-medication: A systematic review and meta-analysis of the burden, risk factors and outcomes in developing countries. BMC Public Health 2015, 15, 742. [CrossRef] 
35. National Institute of Population Research and Training (NIPORT), and ICF. Bangladesh Demographic and Health Survey 2017-18; NIPORT/ICF: Dhaka, Bangladesh, 2020.

36. Zheng, C.; Karkey, A.; Wang, T.; Makuka, G.; van Doorn, R.; Lewycka, S. Determinants of disease prevalence and antibiotic consumption for children under five in Nepal: Analysis and modelling of demographic health survey data from 2006 to 2016. medRxiv 2020. [CrossRef]

37. Lucas, P.J.; Uddin, M.R.; Khisa, N.; Akter, S.S.; Unicomb, L.; Nahar, P.; Islam, M.A.; Nizame, F.A.; Rousham, E.K. Pathways to antibiotics in Bangladesh: A qualitative study investigating how and when households access medicine including antibiotics for humans or animals when they are ill. PLoS ONE 2019, 14, e0225270. [CrossRef] [PubMed]

38. Ababneh, M.A.; Al-Azzam, S.I.; Ababneh, R.; Rababa'h, A.M.; Demour, S.A. Antibiotic prescribing for acute respiratory infections in children in Jordan. Int. Health 2017, 9, 124-130. [CrossRef]

39. Simieneh, M.M.; Mengistu, M.Y.; Gelagay, A.A.; Gebeyehu, M.T. Mothers' health care seeking behavior and associated factors for common childhood illnesses, Northwest Ethiopia: Community based cross-sectional study. BMC Health Serv. Res. 2019, 19, 1-7. [CrossRef]

40. Pusic, M.V. Clinical management of fever in children younger than three years of age. Paediatr. Child Health 2007, 12, 469-472. [CrossRef]

41. Allwell-Brown, G.; Hussain-Alkhateeb, L.; Sewe, M.O.; Kitutu, F.E.; Strömdahl, S.; Mårtensson, A.; Johansson, E.W. Determinants of trends in reported antibiotic use among sick children under five years of age across low-income and middle-income countries in 2005-17: A systematic analysis of user characteristics based on 132 national surveys from 73 countries. Int. J. Infect. Dis. 2021, 108, 473-482. [CrossRef] [PubMed]

42. Jensen, J.N.; Bjerrum, L.; Boel, J.; Jarløv, J.O.; Arpi, M. Parents' socioeconomic factors related to high antibiotic prescribing in primary health care among children aged 0-6 years in the Capital Region of Denmark. Scand. J. Prim. Health Care 2016, 34, 274-281. [CrossRef]

43. Karagiannaki, E. The effect of parental wealth on children's outcomes in early adulthood. J. Econ. Inequal. 2017, 15, 217-243. [CrossRef]

44. Liu, Y.; Ma, Y.; Jiang, N.; Song, S.; Fan, Q.; Wen, D. Interaction between parental education and household wealth on children's obesity risk. Int. J. Environ. Res. Public Health 2018, 15, 1754. [CrossRef] [PubMed]

45. Abdulkadir, M.B.; Abdulkadir, Z.A. A cross-sectional survey of parental care-seeking behavior for febrile illness among under-five children in Nigeria. Alex. J. Med. 2017, 53, 85-91. [CrossRef]

46. Hernán, M.A.; Hernández-Díaz, S.; Werler, M.M.; Mitchell, A.A. Causal knowledge as a prerequisite for confounding evaluation: An application to birth defects epidemiology. Am. J. Epidemiol. 2002, 155, 176-184. [CrossRef] [PubMed]

47. Victora, C.G.; Huttly, S.R.; Fuchs, S.C.; Olinto, M. The role of conceptual frameworks in epidemiological analysis: A hierarchical approach. Int. J. Epidemiol. 1997, 26, 224-227. [CrossRef]

48. Jewell, N.P. Statistics for Epidemiology; CRC Press: Boca Raton, FL, USA, 2003. 